Research Article

\title{
A Study of Data-Driven Enterprise Human Resource Management Model
}

\author{
Jing Yang $\left(1,{ }^{1}\right.$ Lili Lang $\mathbb{C}^{2},{ }^{2}$ and Shaojuan Song $\mathbb{C}^{3}$ \\ ${ }^{1}$ Normal School of Changzhi University, Changzhi, Shanxi 046000, China \\ ${ }^{2}$ Mathematics Section, Changzhi Medical College, Changzhi, Shanxi 046000, China \\ ${ }^{3}$ Biology Section, Changzhi Medical College, Changzhi, Shanxi 046000, China \\ Correspondence should be addressed to Shaojuan Song; cyssj@czmc.edu.cn
}

Received 9 September 2021; Accepted 22 October 2021; Published 26 November 2021

Academic Editor: Gengxin Sun

Copyright (C) 2021 Jing Yang et al. This is an open access article distributed under the Creative Commons Attribution License, which permits unrestricted use, distribution, and reproduction in any medium, provided the original work is properly cited.

With the deepening of diversified and professional business philosophy in large enterprises, enterprises play more and more abundant social functions in society. Sense of mission and honor play an important role in the healthy development of enterprises. With the in-depth integration of enterprise management and computer technology, some human resource management problems related to corporate social responsibility often appear in this process. From the traditional human resource management paradigm to people-oriented social responsibility human resource management, "strengthening effectiveness" has become the main research direction of enterprise management in the electronic age. On this basis, through the discrete modeling method of a large amount of data, this paper creatively puts forward the coupling correlation between corporate social responsibility and enterprise human resource management based on grey correlation algorithm. Compared with the management mode based on trapezoidal data analysis and cluster center adopted in the current mainstream enterprise human resource management research, the innovation of this algorithm is to analyze the dynamic data of corporate social responsibility and enterprise human resources and establish a coupling model related to corporate social responsibility. It can not only realize the dynamic tracking of human resource data, but also make full use of the relevant characteristic information of the coupling relationship between enterprise human resource management and corporate social responsibility. According to the dynamic big data such as employee welfare, employee compensation, employee training, employee overtime, and timeliness of transaction processing, this paper analyzes the social problems such as corporate social responsibility evaluation index, employee turnover rate, and enterprise income, so as to provide theoretical support for enterprise business strategy.

\section{Introduction}

In recent years, China has repeatedly emphasized that the relevant policies related to the responsibility in the process of enterprise development are "legal, ethical, economic, and social" [1]. In the process of enterprise social operation and production, enterprises will unconsciously play the role of labor transfer, and the problem of social responsibility in this process is the top priority. Therefore, research on the optimization of corporate social responsibility in human resources has been carried out, and the evaluation of corporate human resources has been taken as the main research direction [2]. At present, although scholars have put forward a large number of evaluation schemes for the existing corporate social responsibility problems, it is difficult to quantitatively evaluate corporate social responsibility according to its own characteristics in actual human resource management [3]. Most people can only put forward implementation schemes for targeted corporate social responsibility problems based on previous experience, unable to achieve optimal business and social goals [4]. In this context, based on big data technology, this paper dynamically studies the coupling relationship between corporate social responsibility and enterprise human resource management. On this basis, the optimization of human resource allocation in enterprises is analyzed by dynamic neural network modeling method. 
Aiming at the problems of low efficiency, low intelligent office rate, and poor mobility in the management of enterprise human resources, this paper uses big data technology to establish an analysis model suitable for dynamic discrete complex data based on a variety of correlation algorithms and machine learning algorithms and analyzes the coupling relationship between corporate social responsibility and enterprise human resources management. Aiming at the process management allocation of human resources, this paper provides a solution for enterprises. This paper is divided into four chapters according to the research focus of each stage. The first chapter gives a brief overview of the research background and the content planning of this paper; the second chapter briefly introduces the research progress of human resources under corporate social responsibility and the application status of big data analysis technology. The third chapter is mainly based on big data technology, aiming at the theoretical construction, dynamic modeling, and result analysis of the coupling correlation algorithm for corporate social responsibility and enterprise human resource management. The fourth chapter analyzes and calculates the resource optimization of employees in the enterprise by using the method of dynamic neural network modeling and puts forward some construction suggestions based on the calculation results.

Compared with the management model based on ladder data analysis and cluster center used in the current mainstream research on enterprise human resource management, the innovation of this paper is to propose an association algorithm based on grey algorithm to analyze the dynamic data of corporate social responsibility and enterprise human resources and establish a coupling model related to corporate social responsibility. The model can not only realize the dynamic tracking of human resource data, but also make full use of the correlation characteristic information of the coupling relationship between corporate human resource management and corporate social responsibility. Through the dynamic in-depth analysis of relevant ethical data, it can realize the quantitative representation and qualitative analysis of the ethical coupling relationship in the application of corporate social responsibility. Use Hadoop HDFS architecture combined with artificial neural network to analyze the relevant big data generated by human resources process management, customize the personalized performance plan for employees' social responsibility, and structurally optimize the internal human resources management of the enterprise.

\section{Related Work}

Although researchers have studied the enterprise human resource management strategy based on corporate social responsibility for many years, most studies only conduct surface analysis based on social phenomena, the relevant quantitative characteristic indicators are fuzzy, and there is a certain information lag [5].

In recent years, researchers' research hotspots and research methods related to human resource management have also been innovating [6]. Taylor D E and other scholars proposed to study the differences of people's perception of social environment and analyzed the statistical differences of people's fear, risk, and hatred from the perspective of human resource management in the form of interview [7]. Arar K and other scholars proposed an incentive model for human resource management, which shows that, with the rational allocation of characteristic dimensions such as resource management and organizational structure, there is a positive correlation with enterprise energy efficiency [8]. Mas A, according to the grounded theorem, and such scholars designed a course to improve the project management ability of human resources. The effective implementation of the course in enterprises can greatly improve the management efficiency of users [9]. Herrera J and other scholars took the human resource management of a place in Spain as an example, analyzed the decision-making data of human resource managers, and obtained the descriptive characteristics based on the five dimensions of technical management, technical ability, administrative management, administrative ability, and strategic thinking [10]. Sun y and other scholars analyzed more than 50000 data points of 132 enterprises for the problem of corporate environmental protection social responsibility and found that as long as enterprises carry out environment-friendly development, no matter in what form, they can improve the quality of employees and the production efficiency of enterprises [11]. With the development of computer technology, data is gradually becoming the core of operation in all walks of life [12]. At present, algorithms are playing a core role in processing industry big data [13]. Sangdo L, through big data technology, and other scholars developed a real-time monitoring system for preventing network intrusion of nuclear power plant. The use of the system can plan effective network security measures and strengthen the safe operation of nuclear power plant control system [14]. Suh m and other scholars took Korean family health data over 40 years old as samples, analyzed the correlation between hearing loss and vestibular function impairment through big data technology based on improved logistic regression algorithm, and found that low-frequency hearing threshold impairment may cause vestibular function impairment [15]. According to the big data collected by the multisensor fusion technology on the aircraft, GUI g and other scholars successfully predicted the air traffic flow between different regions through the longterm and short-term memory algorithm, providing theoretical support for the traffic planning scheme [16]. Aiming at the lack of research on the combination of big data and human resource management technology, y Zhang and other scholars proposed a theoretical framework of human resource literature big data based on induction and deduction through clustering algorithm, but the framework lacked theoretical guidance and only explored the surface of management methodology [17].

To sum up, it can be seen that the current big data analysis is extensive in the application field, professional in the application field, and diversified in the analysis algorithm [18]. However, in terms of big data engineering problem solutions and human resource management for corporate social responsibility, big data analysis technology has not 
been combined with this to produce guiding research [19]. With less integration with science education, in terms of the structure construction of big data analysis algorithms, most big data analysis algorithms only perform separation calculation for static data, and there are few dynamic algorithm models specially designed for complex dynamic discrete data [20]. Therefore, it is necessary to carry out the research on enterprise human resource management under corporate social responsibility based on big data analysis.

\section{Construction Method of Dynamic Correlation Coupling Model between Corporate Social Responsibility and Enterprise Human Resource Management}

3.1. Application of Relevance Coupling Model in Corporate Social Responsibility and Enterprise Human Resource Management. The emergence of relevance algorithm provides a reliable tool for quantitative research of various engineering problems $[21,22]$. In order to quantitatively study the mechanism of data related to ethical problems, economic problems, and social problems caused by enterprise human resource management under corporate social responsibility, this study introduces the relevance algorithm into the grey algorithm in a variety of correlation coupled subnode attributes, For the disturbance of most quantitative complexity factors to a problem, the solution is mostly based on the solution idea of local first and then overall. Association analysis algorithm is to focus on mining the relationship between data attributes when solving a large amount of data. In other words, the association analysis algorithm can always find "the law that a certain attribute of one thing changes and causes a certain attribute of another thing to change" among a variety of data attributes [23-25]. In the process of solving, the grey algorithm correlation analysis algorithm does not get the overall optimal solution for the problems with a large number of samples, high certainty, or sufficient information but abstractly takes the abscissa as the benchmark, and the trend measurement of different attributes changing with the abscissa as the benchmark. To sum up, the grey correlation coupling algorithm is very suitable for analyzing the multiattribute dynamic process, and the relevant data of enterprise human resource management under the background of corporate social responsibility has the typical characteristics of information fuzziness, which is very suitable for calculating the coupling degree combined with the grey algorithm. Figure 1 shows the schematic diagram of enterprise human resource management under the background of corporate social responsibility based on grey algorithm, because HDFS has high fault tolerance and is deployed on low-cost hardware. For applications with large datasets. The distributed system relaxes some POSIX requirements to realize streaming access to file system data. Therefore, this paper takes the system as the research tool. This study collects and imports the collected sample data of human resource management related flow data into Hadoop HDFS in real time and then analyzes the coupling of corporate social responsibility relevance through the API interface based on python.
3.2. Dynamic Analysis Process of Grey Relational Model of Enterprise Human Resource Management under the Background of Corporate Social Responsibility. The basic idea of the grey correlation model based on enterprise human resource management is to calculate whether the sequence shape approximation of the data related to enterprise human resource management and the data of corporate social responsibility development index is close. The traditional association coupling model is weak in dealing with complex discrete dynamic data. This study makes the traditional sequence dynamic after data mining by introducing big data technology. The basic steps are as follows. Firstly, take the relevant data of enterprise human resource management attributes as the comparison sequence and the corporate social responsibility development index data as the reference sequence. Then, the correlation coefficient between them is calculated, and finally their correlation degree is determined based on the above calculation. Figure 2 shows the flow chart of the calculation process.

Next, the construction of the dynamic grey correlation model will be specifically analyzed. In this study, $\alpha$ is defined as the correlation coefficient and $\Psi$ as the correlation degree. In order to calculate them, $x$ needs to be defined as the mean image of each sequence, $X$ as the matrix of the mean image, $\Delta$ as the matrix of the difference sequence, and $m$ and $M$ as the minimum difference and maximum difference of the two poles. The calculation formulas of $\alpha$ and $\Psi$ are as follows. First, calculate the initial mean image of each sequence:

$$
X_{i}^{\prime}=\frac{X_{i}}{x_{i}(1)}=\left[x_{1}^{\prime}(1), x_{1}^{\prime}(2), \ldots, x_{i}^{\prime}(n)\right], \quad i=0,1,2, \ldots, m \text {. }
$$

Then, calculate the difference sequence:

$$
\begin{aligned}
\Delta_{i}(k) & =\left|x_{0}^{\prime}(k)-x_{i}^{\prime}(k)\right|, \\
\Delta_{i} & =\left[\Delta_{i}(1), \Delta_{i}(2), \ldots, \Delta_{i}(n)\right], \quad i=0,1,2, \ldots, m .
\end{aligned}
$$

Minimum and maximum difference between the following two poles:

$$
\begin{gathered}
M=\max _{i} \max _{k} \Delta_{i}(k), \\
m=\min _{i} \min _{k} \Delta_{i}(k) .
\end{gathered}
$$

Based on the above calculation, the correlation coefficient is obtained $\alpha$ :

$$
\alpha_{0 i}(k)=\frac{m+\beta M}{\Delta_{i}(k)+\beta M}, k=1,2, \ldots, n ; i=1,2, \ldots, n,
$$

where $\beta$ is the coefficient in the range of 0 to 1 , and finally the correlation coefficient can be obtained $\Psi$ :

$$
\Psi_{0 i}=\frac{1}{n} \sum_{k=1}^{n} r_{0 i}(k), \quad k=1,2, \ldots, n ; i=1,2, \ldots, n .
$$

Generally, when $\Psi$ is greater than 0.8 , the reference attribute and contrast attribute are strongly correlated; when $\Psi$ is less than 0.8 and greater than 0.5 , they are moderately 


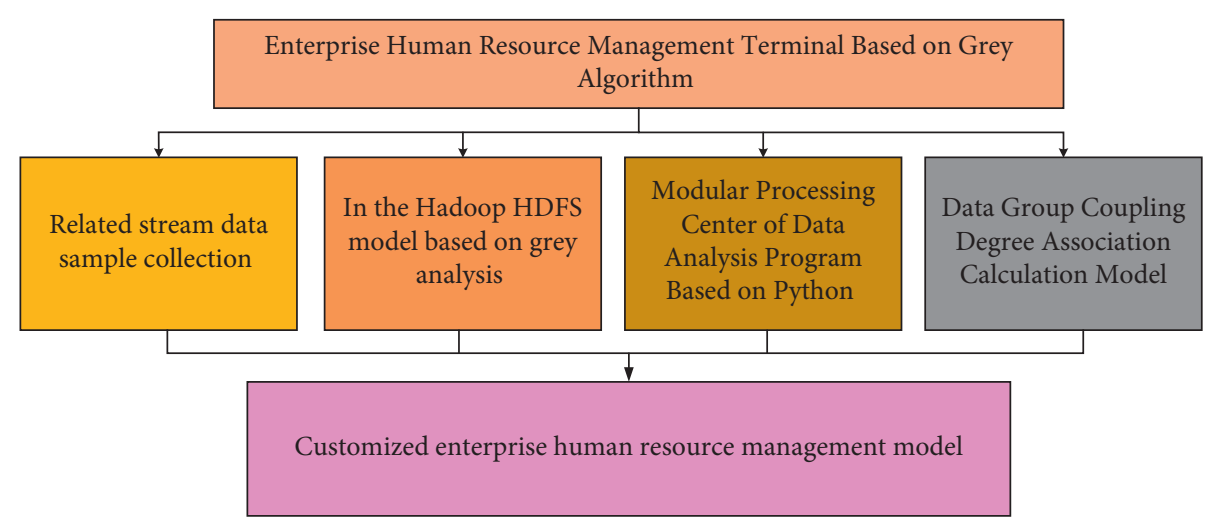

FIGURE 1: Schematic diagram of enterprise human resource management based on grey algorithm.

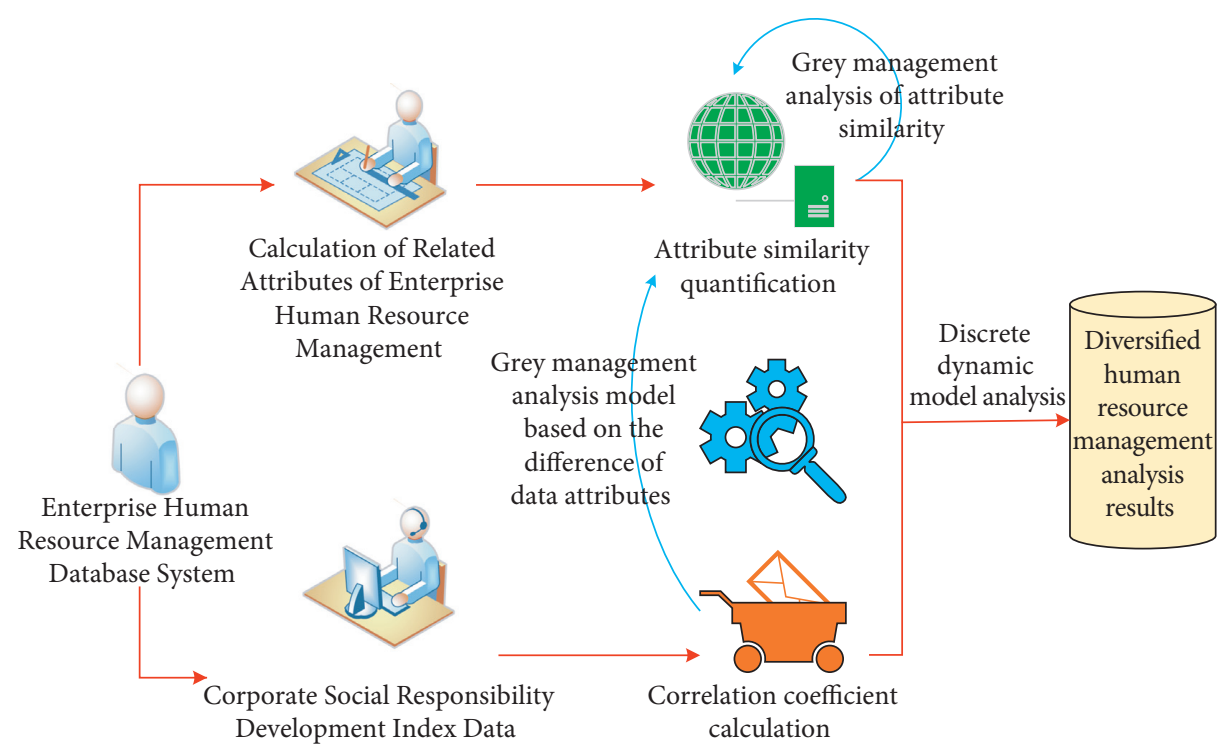

FIGURE 2: The dynamic analytical process of the grey relational model of enterprise human resource management.

correlated; when $\Psi$ is less than 0.5 and greater than 0.3 , they are weakly correlated; and when $\Psi$ is less than 0.3 , they are poorly or even not correlated. According to the calculated correlation coefficient, the correlation degree between the comparison sequence and the reference sequence can be obtained. After completing the calculation, it is necessary to conduct simulation analysis on the data in the process of human resource management. The simulation analysis results of three groups of known data are shown in Figure 3.

As can be seen from Figure 3, in the analysis results of three groups of data groups with different correlation degrees $(0.1 / 0.5 / 0.9)$, with the increase of the number of grey management analysis algorithms, the corresponding hybrid calculation complexity index factors are also different and show a change trend of first increasing, then decreasing, and then increasing, This is because of, through this dynamic correlation degree algorithm to analyze the coupling between things, the new generation of inclusive human resource management features. In the technological innovation scheme, it not only inherits the previously intelligently screened correlation information of human resource management and social responsibility, but also can be better optimized according to the dynamic information. In this way, after several interactive cycles of information, a human resources coupling evaluation model meeting the requirements of relevance is finally generated; that is, the analysis value of enterprise human resources management under the background of corporate social responsibility can approach the normal evaluation value of the actual attribute of corporate social responsibility. In this way, we can quantitatively record the behavior of corporate social responsibility valuation of different types of enterprise human resource management related attributes under dynamic grey correlation calculation. The above is the solution in the process of studying the coupling relationship between corporate social responsibility and enterprise human resource management.

\subsection{Establishment of Prototype Platform of Grey Correlation Model of Enterprise Human Resource Management under the Background of Corporate Social Responsibility. The}




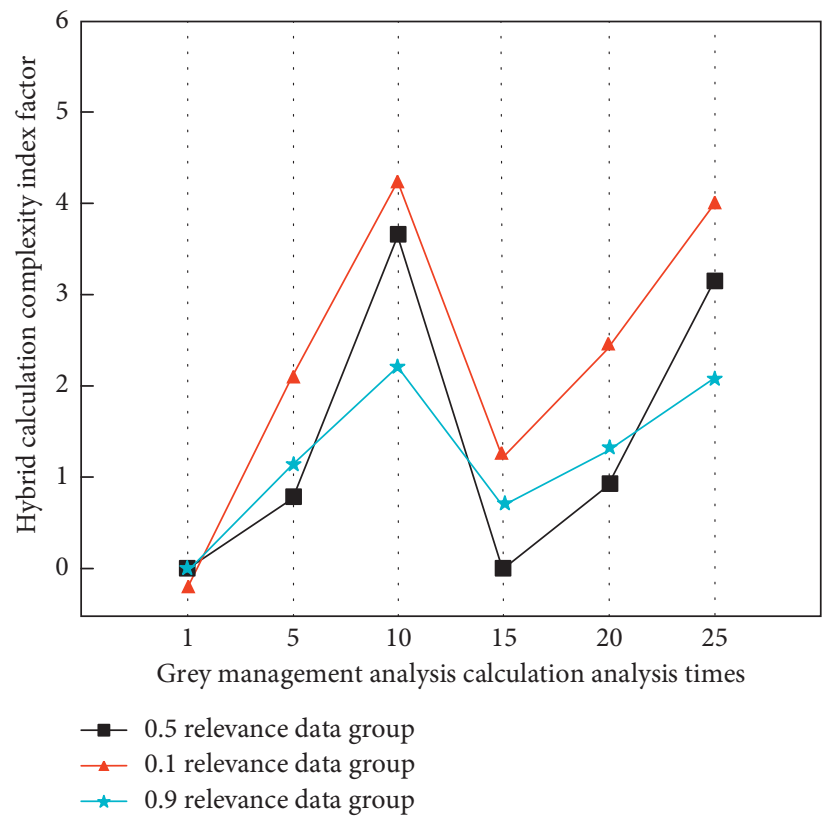

FIGURE 3: Simulation analysis results of 3 sets of known data with different correlation degrees.

construction of grey relational model fusion big data integration system mainly includes three modules: import module, management module, and analysis module. The simulation analysis process of big data system integration discrete dynamic grey analysis model for data is shown in Figure 4.

As can be seen from Figure 4, among the three groups of data groups with different correlation degrees $(0.1 / 0.5 / 0.9)$, with the increase of the completion degree of discrete dynamic grey analysis, the corresponding color coupling degree similarity gradually becomes stable in a certain range. And when the analysis completion degree remains unchanged, the greater the correlation degree, the higher the similarity. This is because the import module extracts the relevant data behavior of enterprise human resource management to provide data support for the analysis module. After the data of the import module is loaded, the big data system imports the extracted enterprise human resource management data into the database of the management module. The data is classified according to different attributes, and the management module has the functions of adding, deleting, and modifying the imported data. The analysis module mainly integrates the dynamic grey correlation algorithm, which belongs to an enhanced correlation algorithm, and its underlying logic has been described above. This study uses Python software, which is brilliant in the field of data processing, as the development language of this part, and develops the PyCharm framework with friendly IDE interface and popular at present, so as to complete the algorithm level analysis of dynamic discrete data related to enterprise human resource management.

3.4. Simulation Experiment and Discussion of Grey Correlation Model of Enterprise Human Resource Management under the Background of Corporate Social Responsibility. This study selects the social responsibility development index of 100 Chinese enterprises released by a research institution in China from 2010 to 2019 as the reference sequence, and sets the annual revenue and annual employee turnover rate of these 100 enterprises as the comparative reference sequence, so as to better reflect the impact of relevant data of enterprise human resource management on corporate social responsibility. The 11 attributes of environmental protection investment, enterprise donation, community welfare investment, salary, overtime, overtime pay, employee training time, employee physical examination, employee holiday welfare, timeliness of enterprise transaction processing, and employee performance reward of these 100 enterprises are used as the comparison sequence. The experimental simulation analysis results of the mainstream ladder data analysis strategy, cluster center data analysis strategy, and grey correlation analysis strategy based on data attribute differences are shown in Figure 5.

The above data are imported into the big data integration system based on dynamic grey correlation model designed in this study year by year. The results are shown in Table 1 .

According to Table 1 and Figure 5, in the experimental simulation analysis results of the mainstream ladder data analysis strategy, cluster center data analysis strategy, and grey correlation analysis strategy based on data attribute difference, among the seven different groups, the data analysis accuracy obtained by using the grey correlation analysis strategy based on data attribute difference is higher than that of the other two methods. This is because the grey management analysis group, before analyzing the data, first quantitatively evaluates the correlation degree of the data and sets the analysis times to varying degrees according to the difference of correlation, so as to realize adaptive analysis in local data analysis, so as to improve the accuracy of the final data analysis results. 


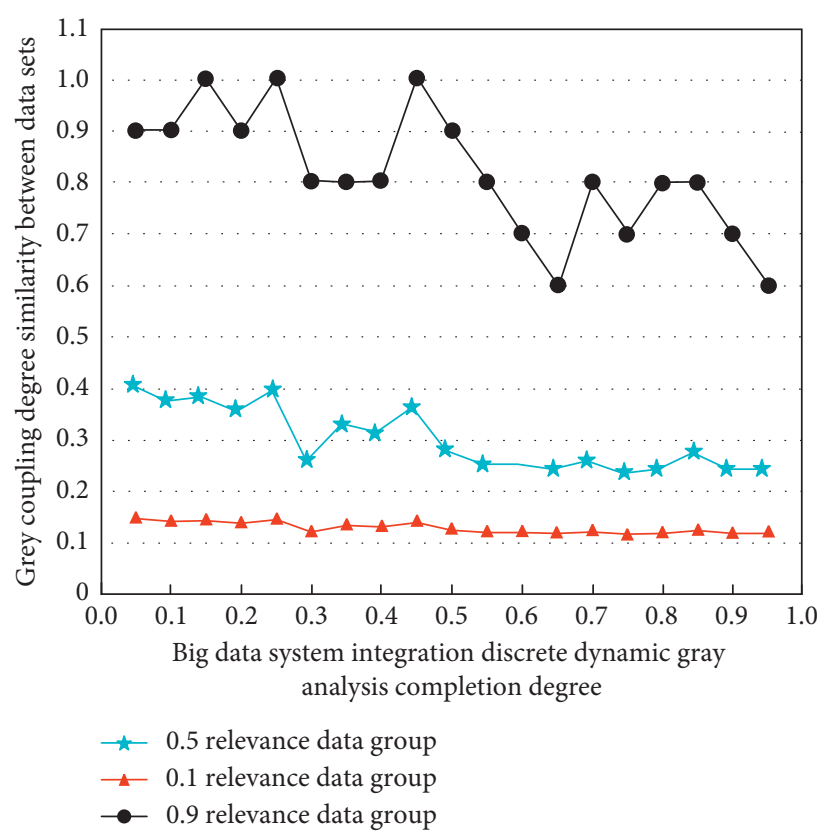

FIGURE 4: Simulation results of the completion and similarity of the discrete dynamic grey analysis of the big data system integration.

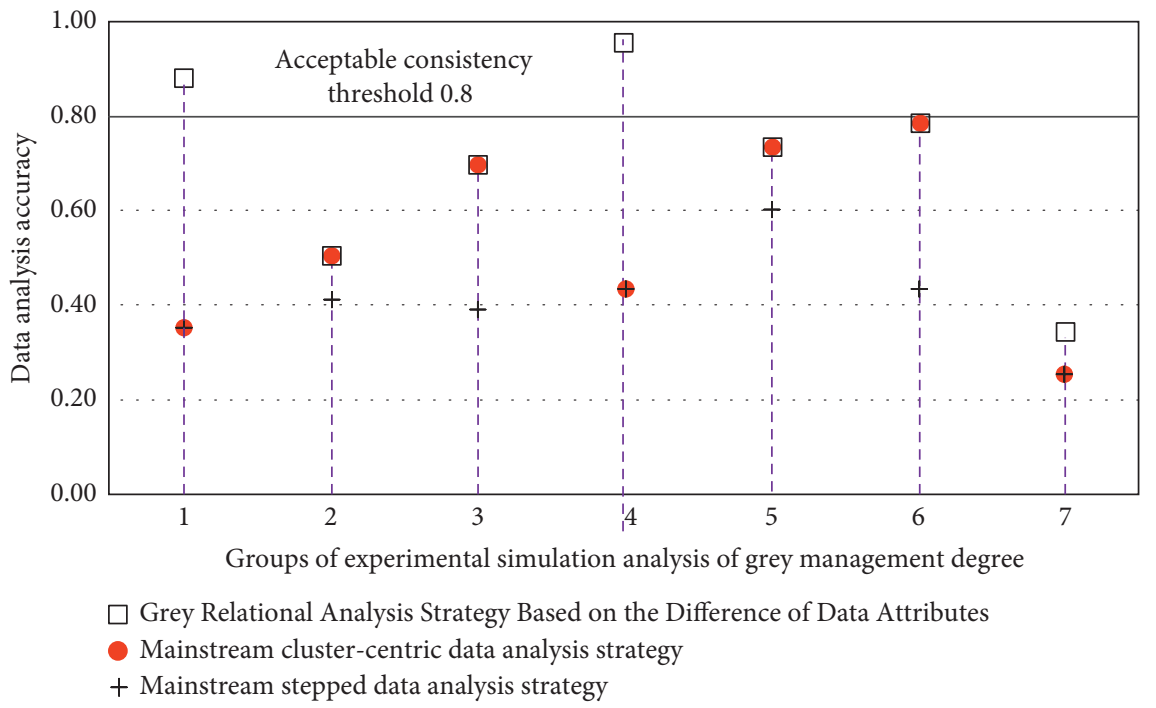

FIGURE 5: Experimental simulation analysis results of two mainstream data analysis strategies and grey management degree.

TABLE 1: Correlation between corporate social responsibility index, corporate revenue, and employee turnover rate and each comparative attribute.

\begin{tabular}{lccc}
\hline Properties of the comparison sequence & Corporate social responsibility index & Enterprise revenue & $\begin{array}{c}\text { Turnover rate of enterprise } \\
\text { employees }\end{array}$ \\
\hline Environmental protection & 0.938 & 0.636 & 0.325 \\
Contribution & 0.927 & 0.860 & 0.168 \\
Community welfare investment & 0.914 & 0.828 & 0.231 \\
Salary of employees & 0.453 & 0.856 & 0.753 \\
Overtime for employees & 0.514 & 0.807 & 0.935 \\
Overtime pay for employees & 0.522 & 0.836 & 0.955 \\
Training time of employees & 0.624 & 0.812 & 0.620 \\
Medical check-up of employees & 0.875 & 0.859 & 0.524 \\
Holiday benefits for employees & 0.806 & 0.431 & 0.677 \\
Efficiency of the company in handling affairs & 0.416 & 0.886 & 0.756 \\
Performance rewards of employees & 0.812 & & 0.730 \\
\hline
\end{tabular}


The relevant data of human resources and corporate social responsibility index are used for calculation, and the data analysis results are shown in Figure 6.

As can be seen from Figure 6, employee holiday benefits, employee performance rewards, and corporate social responsibility index are highly correlated, enterprise transaction processing efficiency, employee physical examination, and corporate social responsibility index are moderately correlated, employee overtime is less correlated with corporate social responsibility index, and its growth rate is also different $(30.8 \%-65.7 \%)$. As a comparison, this study found that the environmental protection investment, charitable donation investment, and community welfare investment of enterprises have a high correlation with the corporate social responsibility index, which is consistent with the expected situation of this study, which proves the accuracy of the model based on dynamic grey correlation algorithm. On the other hand, this study found that, in addition to the two attributes of environmental protection investment and enterprise transaction efficiency, the revenue of the enterprise is highly correlated with other attributes, which reflects that, with the improvement of the revenue of the enterprise, all the responsibilities of the enterprise have been improved in this process. In addition, this study also found that employee overtime, employee overtime pay, and employee turnover rate are highly correlated. To sum up, enterprises should attach great importance to the psychological and physiological humanistic care and related matters such as regular physical examination and regular welfare of employees, actively carry out vocational education for employees, and weigh overtime, so as to better bear the social responsibility in the direction of human resources.

\section{Result Analysis and Discussion}

4.1. Experimental Model Optimization of Artificial Intelligence Neural Network in Human Resource Management Analysis under Corporate Social Responsibility. According to the conclusion drawn in the third chapter of this paper, there is a high correlation between employee performance reward and corporate social responsibility in enterprise human resource management. Employee performance has a two-way impact on employees' self-interest and the overall benefit of the enterprise in the development of the enterprise. Therefore, employee performance plays an important role in the direction of human resource management. This study proposes a big data system based on ant colony Elman dynamic recurrent artificial neural network algorithm, which is used to monitor the performance of enterprise employees in real time. Its basic architecture is similar to the system proposed in Chapter 3 of this paper.

The formula of Elman dynamic recurrent artificial neural network is as follows:

$$
\begin{aligned}
& S(t)=\vartheta\left(w x(t)+\beta O(t)+a_{1}\right) \\
& y(t)=g\left(\varphi S(t)+a_{2}\right) \\
& O(t)=S(t-1)
\end{aligned}
$$

where $\vartheta$ and $g$ represent the transfer functions of the hidden layer and output layer of the artificial neural network, $w$ is the weight from the input layer to the hidden layer, $\varphi$ is the weight from the hidden layer to the feedback layer, $\beta$ is the weight from the feedback layer to the hidden layer, and $a_{1}$ and $a_{2}$ are the thresholds of the hidden layer and output layer. According to the monitoring demand to judge whether the employee performance reward is abnormal, $e(t)$ is defined as the error value between the expected output $y_{1}(t)$ and the actual output $y(t)$ of the neural network at $t$ time, and the square sum of the error of the objective function $E(t)$.

$$
\begin{aligned}
& e(t)=y_{1}(t)-y(t), \\
& E(t)=\frac{1}{2 n} \sum_{t=1}^{T}[e(t)]^{2}
\end{aligned}
$$

where $n$ is the number of samples, and Elman neural network minimizes $E(t)$ by training the weight of each layer. The preliminary results of experimental analysis data of three different methods (ladder data analysis strategy, cluster center data analysis strategy, and grey correlation analysis strategy based on data attribute differences) are shown in Figure 7 .

It can be seen from Figure 7 that the error rate of the grey correlation analysis strategy based on data attribute difference proposed in this study is smaller than that of the other two mainstream methods in the process of processing human resource management data, and it can also be seen from the figure that the curve of the grey correlation analysis strategy is changing, With the increase of the number of iterations, the convergence rate of the function value is significantly higher than that of the other two mainstream methods. After gradient training for multiple groups of experimental data, the change of learning and training time with the increase of data groups is shown in Figure 8.

As can be seen from Figure 8, among the three different methods, the training duration shows an increasing trend with the increase of data groups. When the data group remains unchanged, the training time of the grey correlation analysis strategy based on data attribute difference proposed in this study is longer. This is because this study adopts the grey correlation analysis strategy combined with ant colony algorithm to find the optimal weight and optimal threshold of Elman neural network and continuously iterate to make it meet the fitness accuracy or the maximum number of iterations, complete the training, minimize the square sum of the error between the actual output and the expected output of Elman neural network, and obtain the optimal model, so the time required is higher. The fitness function used in the learning and training process is

$$
J(t)=\frac{1}{2 n} \sum_{t=1}^{T}[e(t)]^{2} .
$$

The normalization function of Elman neural network is 


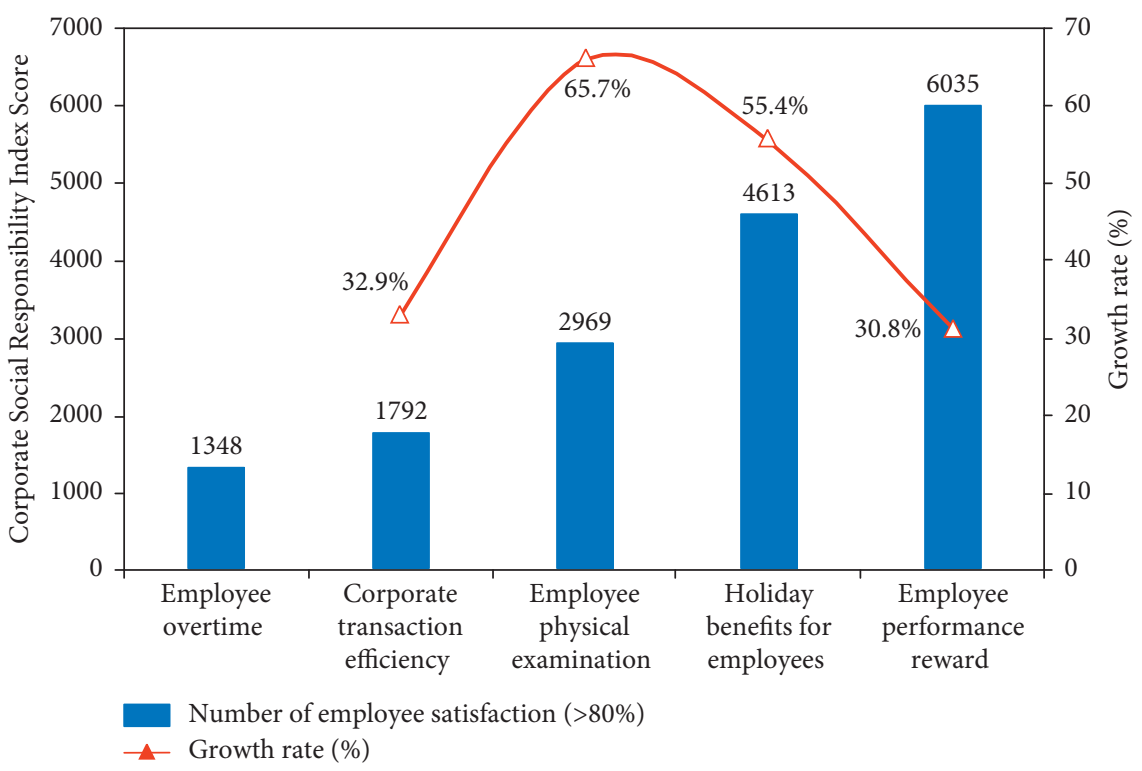

FIGURE 6: Analytical results of human resources related data and corporate social responsibility index.

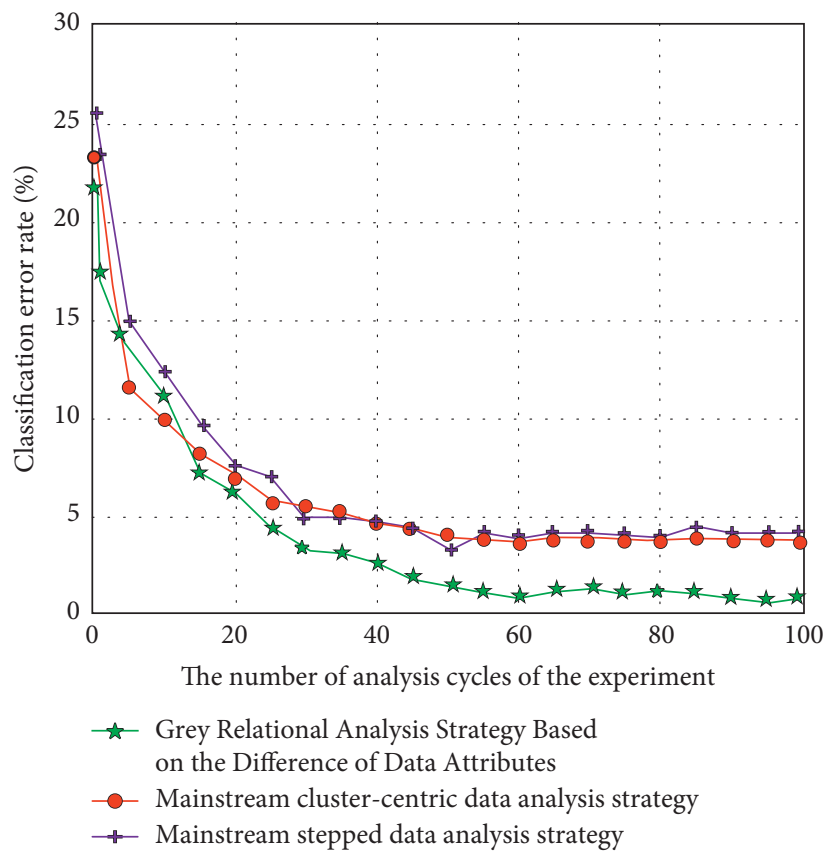

Figure 7: Preliminary results of experimental analysis data of 3 different methods.

$$
Z=\frac{0.8\left(x-x_{\min }\right)}{x_{\max }-x_{\min }}+0.1 .
$$

Inverse normalization is required after prediction:

$$
x=x_{\min }+\frac{(Z-0.1)\left(x_{\max }-x_{\min }\right)}{0.8}
$$

$x_{\min }$ and $x_{\max }$ are the minimum and maximum values of the original data respectively, and $x$ is the original data. The reason for the above setting is that the activation function selected by the neural network is SIGMOD function

$$
n(c)=\frac{1}{1+e^{-c}}
$$

Here, $e$ is the natural constant. 0 is the mapped independent variable, and the value of the independent variable is low in the range of $0.1 \sim 0.9$. Therefore, based on the above theoretical analysis, it can be known that the data in the experimental process will increase with the number of iterations, and the error of the model will be reduced to the allowable range. 


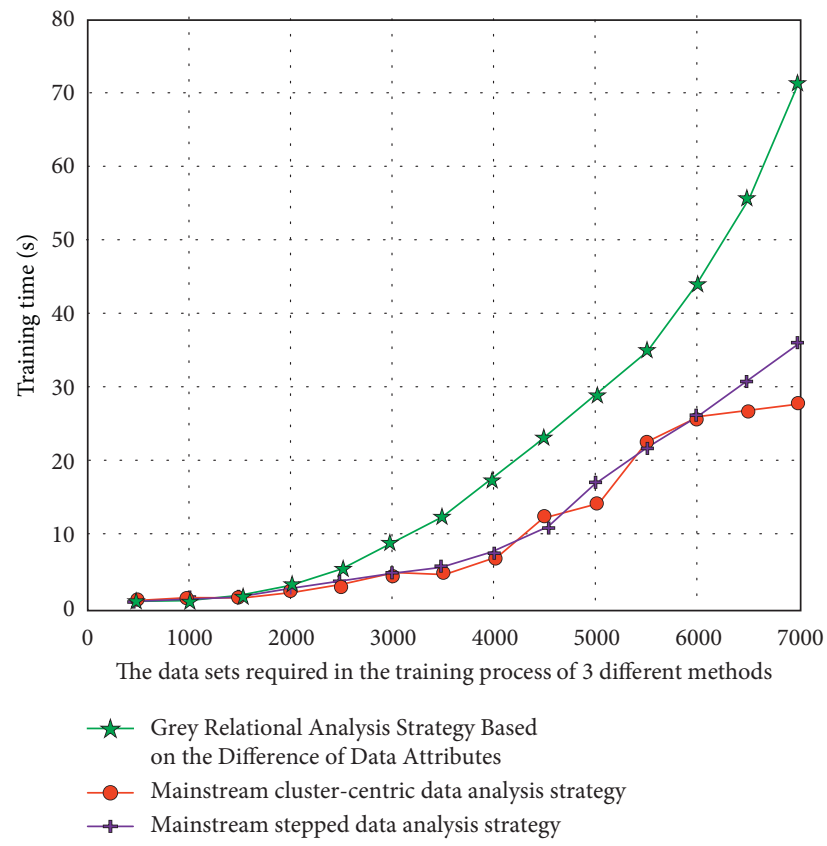

FIGURE 8: 3 different methods of learning and training time changes under different data sets.

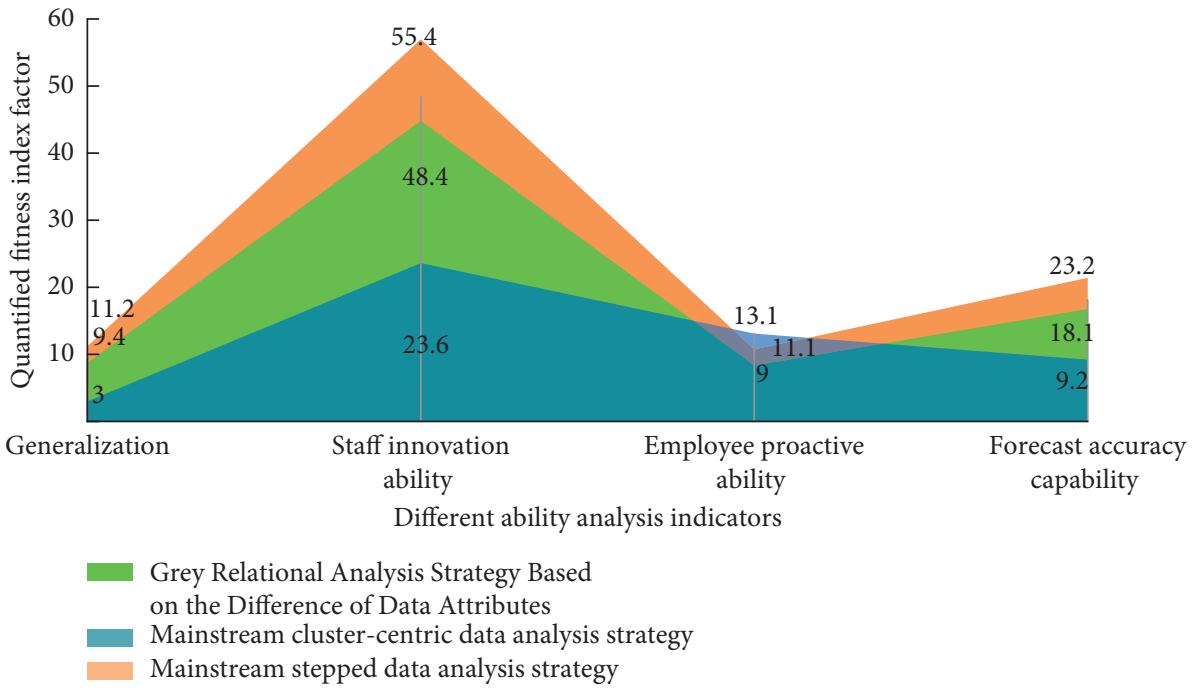

FIGURE 9: Fitting analysis of data involving performance direction of a domestic listed company in the mid-12 months of 2019 by 3 different methods.

4.2. Analysis of Experimental Results. The representative historical performance data of a domestic listed company involving the direction of enterprise human resources management in the middle 12 months of 2019, such as overtime and performance results, are imported into the big data system as the sample data and test data of the prediction model. At the same time, the number of input layer nodes is 14 , the center value of hidden layer is the center value of ant colony, and the maximum number of iterations is 1000 . Figure 9 shows the fitting analysis of the data related to the performance direction of a domestic listed company in the middle 12 months of 2019 by the ladder data analysis model with correction factors, the cluster center data analysis model, and the grey correlation analysis model based on data attribute differences.

As can be seen from Figure 9, according to the calculation results, the model designed in this paper is superior to the other two mainstream data analysis methods and has excellent performance in terms of generalization ability, prediction accuracy ability, employee initiative ability, and employee innovation ability, which has profound guiding significance for the performance direction of enterprise human resource management under the background of corporate social responsibility. On the other hand, we can 
also know that the fitting accuracy of the grey data analysis model designed in this study is very high. It can be predicted that applying the big data system designed in this study to the performance management system can greatly improve the fairness and transparency of enterprise performance management. There are 7 nodes where the predicted data are seriously inconsistent with the actual data, which shows that the model designed in this study has a $100 \%$ prediction success rate for abnormal employee performance. Compared with the management mode based on trapezoidal data analysis and cluster center used in the current mainstream enterprise human resource management research, the correlation algorithm of grey algorithm in this paper has higher generalization ability and prediction accuracy. This not only increases the initiative of employees, but also increases the innovation ability of enterprises.

\section{Conclusion}

How to industrialize big data technology with low cost and high efficiency has always been the industry hotspot of big data technology research. Based on this, aiming at the situation of human resource management under corporate social responsibility, this paper establishes a dynamic model system based on big data and machine learning grey algorithm. Firstly, it introduces the current direction of enterprise human resource management and the development status and shortcomings of various types of big data application technologies. A dynamic model building method based on big data and machine learning grey algorithm is proposed. Secondly, the model construction based on big data grey correlation algorithm is introduced. With the help of this technology, the complex discrete dynamic enterprise data can be analyzed quickly and accurately, and the correlation degree between them can be calculated. Finally, aiming at the problem of employee performance payment, a dynamic model based on ant colony Elman artificial neural network algorithm is proposed to monitor the enterprise employee performance payment. This study establishes a model to analyze the proposed problem in combination with the public data set. The experiment shows that the big data integration system based on ant colony Elman artificial neural network has high accuracy and can well identify the abnormal performance distribution in enterprise human resource management, which is of good help to enterprises to better fulfill their social responsibility in the direction of human resource management.

\section{Data Availability}

The research data used to support the findings of this study are included within the article.

\section{Conflicts of Interest}

The authors declare that they have no conflicts of interest.

\section{References}

[1] Y. Sun, Z. Ding, and Z. Zhang, "Enterprise social media in workplace: innovative use cases in China," IEEE Transactions on Engineering Management, vol. 99, pp. 1-16, 2020.

[2] T. M. Wittman and D. E. Bennett, "A synthesis of research on the human dimensions of sagebrush ecosystem management," Rangeland Ecology \& Management, vol. 78, pp. 155-164, 2021.

[3] K. E. Mills, D. M. Weary, and M. A. G. von Keyserlingk, "Graduate Student Literature Review: challenges and opportunities for human resource management on dairy farms," Journal of Dairy Science, vol. 104, no. 1, pp. 1192-1202, 2021.

[4] N. Zhou, H. Lu, H. Zhao, F. Li, and M. Yang, "Midwifery service and midwifery human resource demand in western China: a cross-sectional study," The Lancet, vol. 394, p. S34, 2019.

[5] B. Choi, T. Ravichandran, and G. C. O’Connor, "Organizational conservatism, strategic human resource management, and breakthrough innovation," IEEE Transactions on Engineering Management, vol. 99, pp. 1-13, 2018.

[6] S. Ozcan, C. O. Sakar, and M. Suloglu, "Human resources mining for examination of R\&D progress and requirements," IEEE Transactions on Engineering Management, vol. 99, pp. 1-16, 2020.

[7] D. E. Taylor, "College students and nature: differing thoughts of fear, danger, disconnection, and loathing," Environmental Management, vol. 64, no. 1, pp. 79-96, 2019.

[8] K. ArarM. A. Nasra et al., "Linking school-based management and school effectiveness: the influence of self-based management, motivation and effectiveness in the Arab education system in Israel," Educational Management Administration \& Leadership, vol. 48, no. 1, pp. 186-204, 2018.

[9] A. Mas, A. L. Mesquida, and R. Colomo-Palacios, "Enhancing the student perception on software project management in computer science," IEEE Transactions on Education, vol. 99, pp. 1-11, 2020.

[10] J. HerreraD. M. Miller et al., “An emergent taxonomy of public personnel management: exploring the task environment of human resource managers in Spanish local government," Public Personnel Management, vol. 47, no. 4, pp. 445-471, 2018.

[11] Y. Sun, J. Du, and S. Wang, "Environmental regulations, enterprise productivity, and green technological progress: large-scale data analysis in China," Annals of Operations Research, no. 1, pp. 1-16, 2019.

[12] T. Nguyen, R. Gosine, and P. Warrian, "A systematic review of big data analytics for oil and gas industry 4.0," IEEE Access, vol. 99, p. 1, 2020.

[13] D. Dai and S. Boroomand, "A review of artificial intelligence to enhance the security of big data systems: state-of-art, methodologies, applications, and challenges," Archives of Computational Methods in Engineering, pp. 1-19, 2021.

[14] L. Sangdo and H. Jun-Ho, "An effective security measures for nuclear power plant using big data analysis approach," The Journal of Supercomputing, vol. 75, no. 3, pp. 1-28, 2018.

[15] M. J. Y. Suh, H. J. Yi, H. J. Kim, and S. H. Kim, "Is asymmetric hearing loss a risk factor for vestibular dysfunction? Lesson from big data analysis based on the Korean national health and nutrition survey," Otology \& Neurotology, vol. 40, no. 10, pp. 1339-1345, 2019. 
[16] G. Gui, Z. Zhou, J. Wang, F. Liu, and J. Sun, "Machine learning aided air traffic flow analysis based on aviation big data," IEEE Transactions on Vehicular Technology, vol. 69, no. 5, pp. 4817-4826, 2020.

[17] Y. Zhang, S. Xu, L. Zhang, and M. Yang, "Big data and human resource management research: an integrative review and new directions for future research," Journal of Business Research, vol. 133, pp. 34-50, 2021.

[18] K. Lu, J. Liu, X. Zhou et al., "A review of big data applications in urban transit systems," IEEE Transactions on Intelligent Transportation Systems, vol. 99, pp. 1-18, 2020.

[19] M. Bracher-Smith, K. Crawford, and V. Escott-Price, "Machine learning for genetic prediction of psychiatric disorders: a systematic review," Molecular Psychiatry, pp. 1-10, 2020.

[20] J. Li, "Intelligent user association algorithm in heterogeneous wireless cellular networks," IET Communications, vol. 13, no. 19, pp. 3244-3252, 2019.

[21] J. Wang, Y. Zeng, S. Wei et al., "Multi-sensor track-to-track association and spatial registration algorithm under incomplete measurements," IEEE Transactions on Signal Processing, vol. 99, p. 1, 2021.

[22] Y. Zhang, S. Ding, L. Wang et al., "Chameleon algorithm based on mutual k-nearest neighbors," Applied Intelligence, vol. 51, no. 3, pp. 1-14, 2020.

[23] X. Ge, X. Li, H. Jin, J. Cheng, and V. C. M. Leung, "Joint user association and user scheduling for load balancing in heterogeneous networks," IEEE Transactions on Wireless Communications, vol. 17, no. 5, pp. 3211-3225, 2018.

[24] M. Güder and N. K. Iekli, "Multi-modal video event recognition based on association rules and decision fusion," Multimedia Systems, vol. 24, no. 1, pp. 55-72, 2018.

[25] S. M. P. Everwijn, A. I. L. Namburete, N. Geloven et al., "The association between flow and oxygenation and cortical development in fetuses with congenital heart defects using a brain-age prediction algorithm," Prenatal Diagnosis, vol. 41, no. 1, pp. 43-51, 2021. 